\title{
Preoperative assessment clinics and case cancellations: a prospective study from a large medical center in China
}

\author{
Shiwen Liu", Xu Lu", Ming Jiang, Weishan Li, Ailun Li, Fang Fang, Jing Cang \\ Department of Anesthesiology, Zhongshan Hospital, Fudan University, Shanghai, China \\ Contributions: (I) Conception and design: J Cang, F Fang; (II) Administrative support: J Cang; (III) Provision of study materials or patients: X Lu, \\ M Jiang, W Li; (IV) Collection and assembly of data: S Liu, A Li; (V) Data analysis and interpretation: S Liu, F Fang; (VI) Manuscript writing: All \\ authors; (VII) Final approval of manuscript: All authors. \\ \#These authors contributed equally to this work. \\ Correspondence to: Fang Fang; Jing Cang. Department of Anesthesiology, Zhongshan Hospital, Fudan University, Shanghai, China. \\ Email: jerryfang81@hotmail.com; cangjing_zs@sina.com.
}

Background: Preoperative assessment clinics have great benefits in reducing surgical cancellations, saving hospital resources and improving patient satisfaction. However, previous studies did not focus on patients with comorbidities. With advancements in medicine and aging population, the number of elderly patients with multiple comorbidities is increasing. This study was designed to assess the effectiveness of a preoperative assessment clinic for patients with multiple comorbidities.

Methods: This prospective, observational study enrolled patients with multiple comorbidities from Nov 1, 2019 to Oct 31, 2020 in a tertiary teaching hospital in China. Patients either visited the preoperative assessment clinic before admission or received an anesthesia consultation after admission. The impact of clinic visits on operating room cancellations, length of hospital stay before surgery, length of hospital stay after surgery, major postoperative complications, incidence of postoperative intensive care unit (ICU) admission, readmission to any hospital within 30 days after surgeries and total in-hospital costs were analyzed.

Results: A total of 326 eligible cases were included. Eighty-seven of 108 cases who visited the clinic before admission were scheduled for selective surgeries. In all, 218 patients received an anesthesia consultation after admission. The cancellation rate in the inpatient group was $7.80 \%$, while no surgeries were cancelled in preclinic group $(\mathrm{P}=0.016)$. A preoperative assessment clinic visit statistically decreased the length of inhospital stays before surgery from 93.02 to $76.11 \mathrm{~h}(\mathrm{P}=0.010)$. After propensity score matching, significant differences in operating room cancellations $(0$ vs. 6.48\%; $\mathrm{P}=0.015)$ and length of stay before surgery $(76.11$ vs. $92.22 \mathrm{~h} ; \mathrm{P}=0.038$ ) persisted between two groups. No significant differences between the two groups were found in terms of prognosis, including major postoperative complications, incidence of postoperative ICU admissions, and readmissions to any hospital within 30 days $(\mathrm{P}>0.05)$.

Conclusions: Among patients with comorbidities undergoing major surgeries, a preoperative assessment clinic visit was more efficient than an anesthesia consultation after admission. These findings may provide impetus for the opening of preoperative assessment clinics for critical patients in China.

Keywords: Preoperative assessment clinic; cancellation; anesthesia consultation; length of stay; efficiency

Submitted Aug 19, 2021. Accepted for publication Sep 27, 2021.

doi: 10.21037/atm-21-4665

View this article at: https://dx.doi.org/10.21037/atm-21-4665 


\section{Introduction}

In China, traditionally, patients with comorbidities have consultations with anesthesiologists after admission. After consultations, patients either continue onto surgery or face delays, if not cancellations, of surgeries. Cancellations of scheduled surgical procedures are a major problem in perioperative medicine and have negative effects on operating room (OR) economics $(1,2)$. For patients scheduled for selective surgeries, case cancellation might lead to unnecessary hospital stays, additional costs, and organizational problems for surgeons and anesthesiologists $(3,4)$. In addition, delays or cancellations of planned procedures can result in significant emotional distress, repeated preoperative fasting, and extra expenses for patients $(5,6)$.

At the end of 2017, the National Health Commission of People's Republic of China issued a policy to encourage the opening of an anesthesia clinic in the context of perioperative medicine (7). In response to the policy, our tertiary teaching hospital started preoperative assessment clinics (PACs) for major surgeries on Nov 1, 2019.

Most medical reasons for cancellations are inappropriate medications (warfarin, aspirin, clopidogrel), abnormal pre-operative investigations (requiring further assessment prior to surgery), untreated or investigated medical condition (hypertension, bradycardia) (8). Preoperative assessment clinics are designed to optimize patients' medical conditions as well as hospital resource utilization before selective surgery and anesthesia (9). In the clinic, anesthesiologists lead the clinic and assess the physical condition of patients, adjusting medications, treating comorbidities, functional training, identifying those who are at high risk for anesthesia and those requiring extensive management before surgery thus reducing cancellations for these patients $(3,10)$. Surgeons assess patients who need to visit $\mathrm{PAC}$ and do not participate in the medical activities in the clinic. If the patient does not meet the criteria for surgery, both anesthesiologists and surgeons decide whether the case should be cancelled $(3,10)$. The anesthesiologistled preoperative clinics have been shown to have many advantages, such as identifying undiagnosed medical problems, improving the management of operating room resources, reducing surgical cancellations, and improving patient safety and satisfaction (11-13).

Previous studies showed that preoperative assessment clinic significantly reduced operation room cancellations $(2,3,8)$. However, these studies compared the outcome of PAC patients with non-consultation patients. Fewer studies focused on critically ill patients scheduled for selective surgeries with multiple comorbidities. A multicenter study showed that a higher case cancellation rate in university hospitals, which might be due to the complexity of patients' medical conditions, meaning that PACs are more indispensable for patients with multiple comorbidities (14).

We therefore set out this prospective study to assess the benefits of a PAC in a tertiary teaching hospital in China. We hypothesized that a preoperative clinic visit would decrease cancellations, unnecessary admissions, and medical expenses in patients with multiple comorbidities. We present the following article in accordance with the STROBE reporting checklist (available at https://dx.doi. org/10.21037/atm-21-4665).

\section{Methods}

\section{Study design}

This single center prospective cohort study enrolled patients from Nov 1, 2019 to Oct 31, 2020 in Zhongshan Hospital, Fudan University, Shanghai, China. All procedures performed in this study involving human participants were in accordance with the Declaration of Helsinki (as revised in 2013). The study was approved by ethics board of clinical trial (No.: NCT03665987) and informed consent was taken from all the patients.

Patients with multiple comorbidities, who were not receiving proper treatment were included. Patients under 18 years, who were undergoing emergency surgeries and had no comorbidities [i.e., American Society of Anesthesiologists (ASA) I] were excluded from the study.

After considering surgeries in surgical clinics, those with multiple comorbidities, who were not receiving proper treatments, were assigned by the surgeon to visit or not visit the PAC.

In the PAC, the anesthesiologist assessed the physical conditions of the patient, adjusting medications (warfarin, clopidogrel), treating investigated comorbidities (hypertension, bradycardia), functional training, referring assessment by medical team (cardiologist, respiratory physician). If both the surgeon and the anesthesiologist believed that the case was not ready for surgery, the case would not be scheduled for surgery. If patient went through PAC, the patient was scheduled for the surgery and admitted to hospital. On the day before surgery, the anesthesiologist and surgeon would perform the preoperative assessment. If they believed that the patient did not meet the criteria for surgery, the case would be cancelled.

For patients who bypassed PAC and were admitted to 


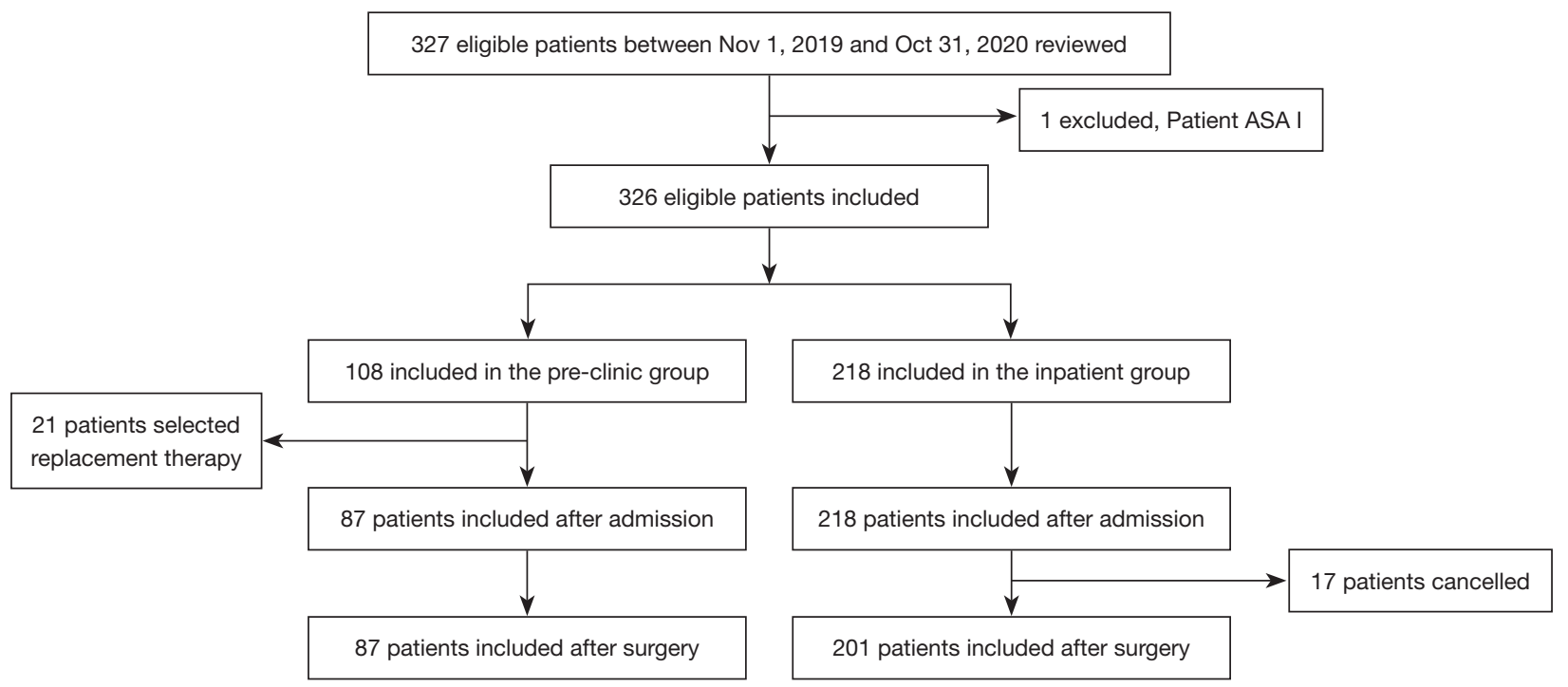

Figure 1 Cohort structure and missing data for patients with preclinic visits $v s$. anesthesia consultations after admission.

hospital, the anesthesia consultation was conducted at least 12 hours before the scheduled surgery. If the case was not ready for surgery, the surgery would be cancelled by the surgeon and anesthesia team.

The two groups did not receive any additional interventions following selective surgery.

Major surgeries in this study included surgeries graded III or IV.

\section{Outcomes}

The primary outcome was operating room cancellations of the surgeries.

The secondary outcomes were major complications, the incidence of postoperative intensive care unit (ICU) admissions and readmissions to any hospital within 30 days of the patients who eventually completed the surgery. In addition, length of hospital stay before surgery, length of hospital stay after surgery and hospitalization expenses were analyzed as secondary outcomes.

Preoperative comorbidities and major complications were defined by the International Classification of Diseases Tenth Revision (ICD-10) diagnostic codes. Major complications were defined as those diagnosed for the first time postoperatively or aggravated after surgery.

\section{Statistical analysis}

Statistical analyses were performed using the Statistical
Product and Service Solutions 22 (SPSS Inc., Chicago, IL, USA) statistical software. Continuous variables were compared using analysis of variance or the KruskalWallis test, while proportions were compared using the chi-square or Fisher's exact test. The Pearson chi-square test was used to analyze the rates of cancellation. Binary logistic regression analysis was performed to determine prognostic factors associated with preclinic visits. Multiple logistic regression analysis was used to examine the effect of preclinic visits on cancellation rates after adjusting for major complications, the incidence of postoperative ICU admissions and readmissions to any hospital within 30 days.

Patients in the two groups were likely to differ systematically due to the small number of cases included in the sample. In particular, gender bias might exist in this type of research. Therefore, propensity scores were estimated using multivariable logistic regression with receipt of a visit to preclinic as the dependent variable and covariates decided upon a priori as independent variables (sex, age, and ASA states).

All statistical analyses were performed separately for each operative site. A P value of 0.05 or less was considered as indicating statistical significance.

\section{Results}

\section{Preoperative and intraoperative status}

This study enrolled 327 patients from Nov 1, 2019 to Oct 31, 2020 (Figure 1). One patient was excluded 
Table 1 Baseline characteristics of the patients

\begin{tabular}{|c|c|c|c|c|c|c|}
\hline & \multicolumn{3}{|c|}{ Observed data $(n=326)$} & \multicolumn{3}{|c|}{ Propensity score matched data $(n=216)$} \\
\hline Age, mean $\pm S D$, years & $67.59 \pm 12.597$ & $69.09 \pm 10.966$ & 0.270 & $67.59 \pm 12.597$ & $67.73 \pm 12.428$ & 0.913 \\
\hline III & 36 (33.33) & $33(15.14)$ & & $36(33.33)$ & $32(29.63)$ & \\
\hline $\begin{array}{l}\text { Age-adjusted Charlson comorbidity } \\
\text { index, mean } \pm S D\end{array}$ & $6.06 \pm 1.521$ & $5.99 \pm 1.577$ & 0.724 & $6.06 \pm 1.521$ & $5.91 \pm 1.673$ & 0.241 \\
\hline \multicolumn{7}{|l|}{ No. of comorbidities, n (\%) } \\
\hline 3 & $24(22.22)$ & $36(16.51)$ & 0.211 & $24(22.22)$ & $21(19.44)$ & 0.263 \\
\hline$\geq 4$ & $7(6.48)$ & $14(6.42)$ & 0.984 & $7(6.48)$ & $6(5.56)$ & 0.622 \\
\hline Hypertension, n (\%) & $57(52.78)$ & $107(49.08)$ & 0.556 & $57(52.78)$ & $46(42.59)$ & 0.215 \\
\hline Coronary artery disease, n (\%) & $24(22.22)$ & $58(26.61)$ & 0.391 & $24(22.22)$ & $27(25.00)$ & 0.433 \\
\hline Arrhythmia, n (\%) & $11(10.19)$ & $43(19.72)$ & 0.029 & $11(10.19)$ & $21(19.44)$ & 0.053 \\
\hline Congestive heart failure, $\mathrm{n}(\%)$ & $15(13.89)$ & $22(10.09)$ & 0.309 & $15(13.89)$ & $13(12.04)$ & 0.845 \\
\hline Peripheral vascular disease, n (\%) & $3(2.78)$ & $11(5.05)$ & 0.509 & $3(2.78)$ & $2(1.85)$ & 0.535 \\
\hline
\end{tabular}

$\mathrm{SD}$, standard deviation; ASA, American Society of Anesthesiologists.

since she was ASA I and visited the PAC by herself. A total of 326 patients were included in this prospective study (108 in the preclinic group, 218 in the inpatient group). Age, preoperative complications, ASA states, ageadjusted Charlson comorbidity index (aCCI) scores and preoperative laboratory examination showed no statistical differences between groups $(\mathrm{P}>0.05$; Tables 1,2). Patients in the inpatient group received more IV grade surgeries and abdominal surgeries than those in the preclinic group $(\mathrm{P}=0.038 ; \mathrm{P}=0.004$; Table 3). No statistical differences were observed in operation time, intraoperative blood loss, and fluid transfusion between the two groups $(\mathrm{P}>0.05$; Table 3$)$.

\section{Primary outcomes}

In the preclinic group, 21 patients (19.44\%) selected replacement therapy due to severe comorbidities and, therefore, were not suitable for surgery and anesthesia. All the patients admitted after attending the PAC completed the scheduled surgeries without delay or cancellation. Seventeen patients $(7.80 \%)$ in the inpatient group cancelled the surgery after admission. The number of operating cancellations in the inpatient group $(7.80 \%)$ was significantly higher than that in the preclinic group (0\%) [risk ratio (RR), 1.056; 95\% confidence interval (CI), 1.032- 
Table 2 Preoperative laboratory examination for surgical cases

\begin{tabular}{|c|c|c|c|c|c|c|}
\hline & \multicolumn{3}{|c|}{ Observed data $(n=288)$} & \multicolumn{3}{|c|}{ Propensity score matched data $(n=188)$} \\
\hline $\mathrm{Hb}, \mathrm{g} / \mathrm{L}$ & $120.885 \pm 24.4870$ & $122.144 \pm 22.4438$ & 0.671 & $120.885 \pm 24.4870$ & $118.933 \pm 24.4454$ & 0.494 \\
\hline ALT, U/L & $17.996 \pm 11.4987$ & $17.577 \pm 10.2120$ & 0.776 & $17.996 \pm 11.4987$ & $17.827 \pm 9.1677$ & 0.996 \\
\hline AST, U/L & $20.310 \pm 7.0699$ & $20.284 \pm 8.0302$ & 0.979 & $20.310 \pm 7.0699$ & $20.702 \pm 7.8492$ & 0.616 \\
\hline ALB, g/L & $42.517 \pm 5.6480$ & $40.995 \pm 5.1396$ & 0.026 & $42.517 \pm 5.6480$ & $40.981 \pm 6.2566$ & 0.099 \\
\hline $\mathrm{Cr}, \mu \mathrm{mol} / \mathrm{mL}$ & $89.908 \pm 64.8463$ & $102.378 \pm 99.3884$ & 0.284 & $89.908 \pm 64.8463$ & $116.029 \pm 142.0791$ & 0.103 \\
\hline cTnT, ng/mL & $0.0156 \pm 0.01342$ & $0.0164 \pm 0.01959$ & 0.750 & $0.0156 \pm 0.01342$ & $0.0203 \pm 0.03540$ & 0.267 \\
\hline CK-MB, ng/mL & $1.9290 \pm 1.83170$ & $2.3768 \pm 4.63359$ & 0.442 & $1.9290 \pm 1.83170$ & $2.9483 \pm 6.16291$ & 0.175 \\
\hline
\end{tabular}

Data are shown as mean \pm standard deviation. Hb, Hemoglobin; ALT, aminoleucine transferase; AST, aspartate aminotransferase; Tbil, total bilirubin: ALB, albumin; Cr, creatinine; cTnT, cardiac troponin T; CK-MB, creatine kinase-MB.

Table 3 Operative conditions

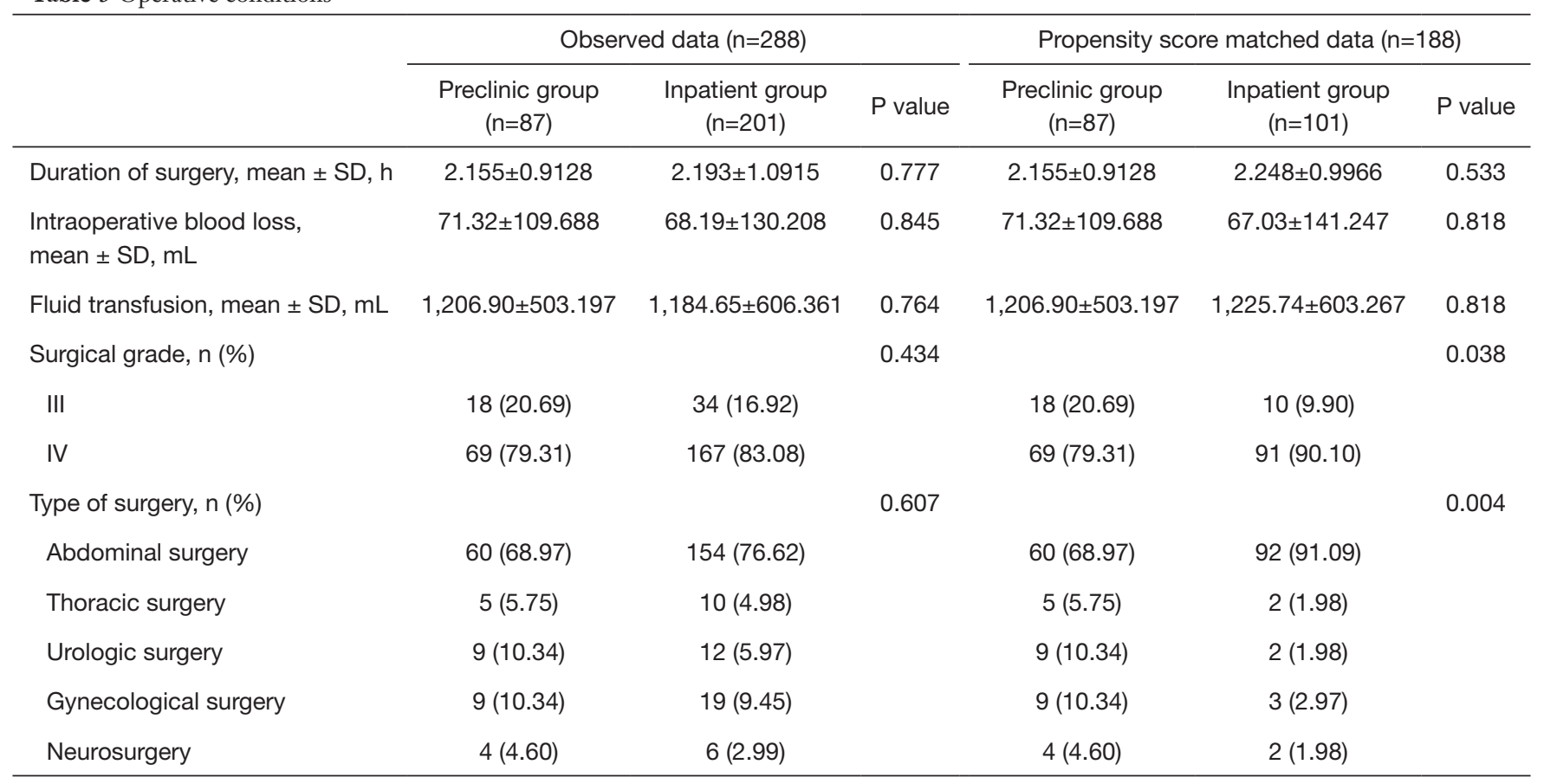

SD, standard deviation.

\subsection{3; $\mathrm{P}=0.016 ;$ Table 4].}

After propensity score matching, the number of operating cancellations in the inpatient group $(6.48 \%)$ was still significantly higher than that in the preclinic group $(0 \%)$ (RR, 1.070; 95\% CI, 1.017-1.124; $\mathrm{P}=0015$; Table 4).

In cases who selected replacement therapy, the medical status in the preclinc group was comparable to those who in the inpatient group $(\mathrm{P}>0.05$; Table 5$)$. The cancelled cases in the inpatient group cost 13,057.74 RMB [standard deviation (SD), 10,125.03 RMB] during hospitalization, which is equivalent to one third of per capita disposable income $(32,189 \mathrm{RMB})$ in China in 2020 (15).

\section{Secondary outcomes}

Major complications, incidence of postoperative ICU admissions 
Table 4 Primary outcome in the study cohort

\begin{tabular}{|c|c|c|c|c|c|c|c|c|c|c|c|c|}
\hline & \multicolumn{6}{|c|}{ Observed data $(n=305)$} & \multicolumn{6}{|c|}{ Propensity score matched data $(n=195)$} \\
\hline & $\begin{array}{c}\text { Preclinic } \\
\text { group } \\
(n=87)\end{array}$ & $\begin{array}{c}\text { Inpatient } \\
\text { group } \\
(\mathrm{n}=218)\end{array}$ & $\begin{array}{c}\mathrm{RR} \\
(95 \% \mathrm{Cl})\end{array}$ & $P$ value & $\begin{array}{c}\mathrm{RR} \\
(95 \% \mathrm{Cl})\end{array}$ & $P$ value & $\begin{array}{l}\text { Preclinic } \\
\text { group } \\
(n=87)\end{array}$ & $\begin{array}{c}\text { Inpatient } \\
\text { group } \\
(n=108)\end{array}$ & $\begin{array}{c}\mathrm{RR} \\
(95 \% \mathrm{Cl})\end{array}$ & $P$ value & $\begin{array}{c}\mathrm{RR} \\
(95 \% \mathrm{Cl})\end{array}$ & $P$ value \\
\hline $\begin{array}{l}\text { Operating room } \\
\text { cancellation }\end{array}$ & $0(0)$ & $\begin{array}{c}17 \\
(7.80 \%)\end{array}$ & $\begin{array}{c}1.085 \\
(1.044-1.127)\end{array}$ & 0.007 & $\begin{array}{c}1.056 \\
(1.032-1.223)\end{array}$ & 0.016 & $0(0)$ & $7(6.48 \%)$ & $\begin{array}{c}1.038 \\
(1.001-1.078)\end{array}$ & 0.016 & $\begin{array}{c}1.070 \\
(1.017-1.124)\end{array}$ & 0.015 \\
\hline
\end{tabular}

$\mathrm{RR}$, risk ratio; $\mathrm{Cl}$, confidence interval.

Table 5 Baseline characteristics of the cancellation cases

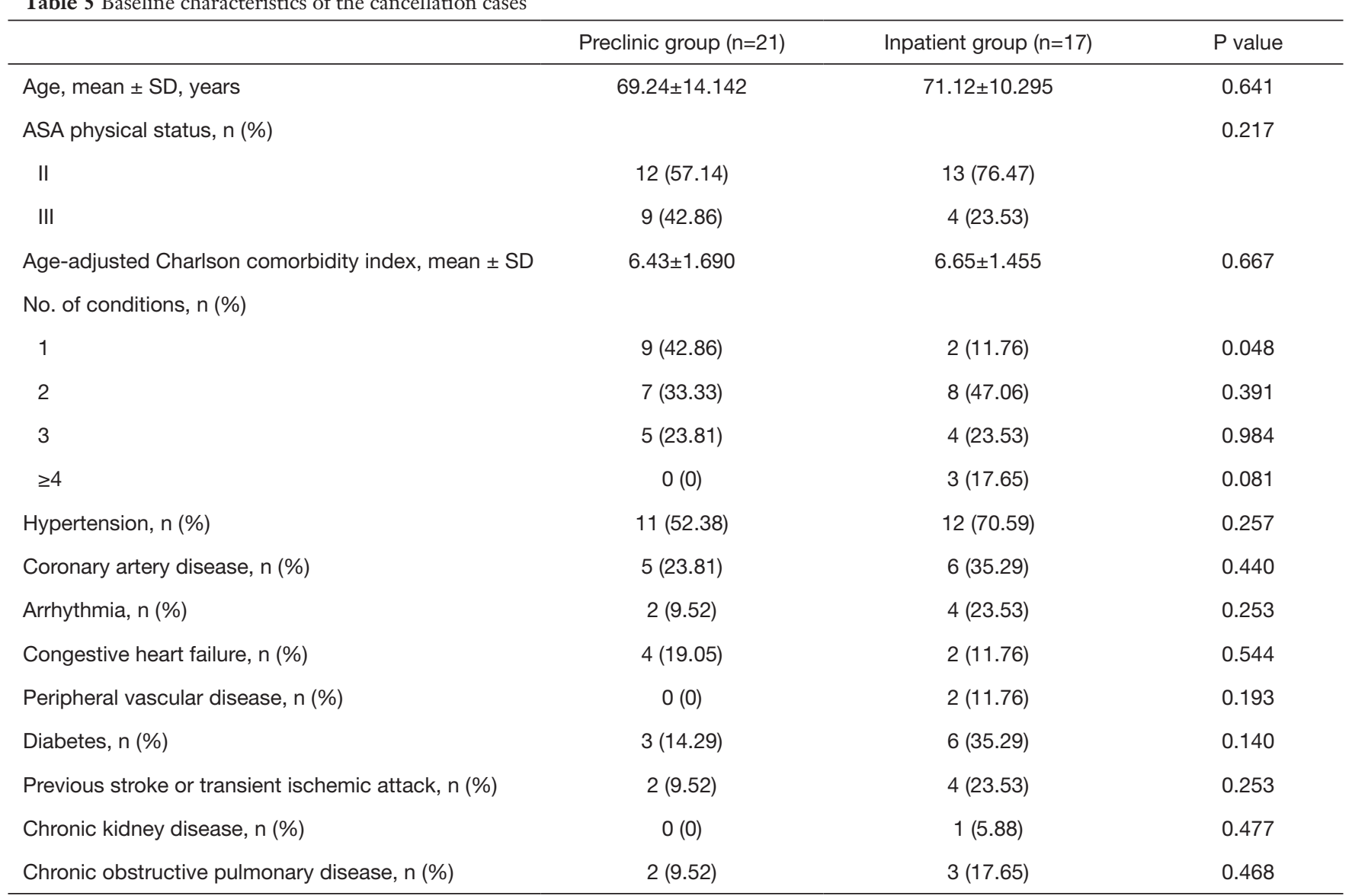

$\mathrm{SD}$, standard deviation; ASA, American Society of Anesthesiologists.

and hospital readmissions within 30 days showed no statistical differences between the two groups $(\mathrm{P}>0.05$, Table 6).

Analysis showed that a PAC visit was significantly associated with a decrease in the length of hospital stay before surgery (76.11 vs. $93.02 \mathrm{~h} ; \mathrm{P}=0.010$; Table 6). Propensity score matched data also showed a significant difference in the length of hospital stay before surgery (76.11 vs. $92.22 \mathrm{~h}, \mathrm{P}=0.038$; Table 6).

There were no statistical differences between the two groups in the length of hospital stays after surgery, hospitalization expenses, and hospitalization expenses without surgical costs $(\mathrm{P}>0.05$; Table 6$)$. The follow-up data on postoperative laboratory examinations showed no statistical differences between the two groups $(\mathrm{P}>0.05$; Table 


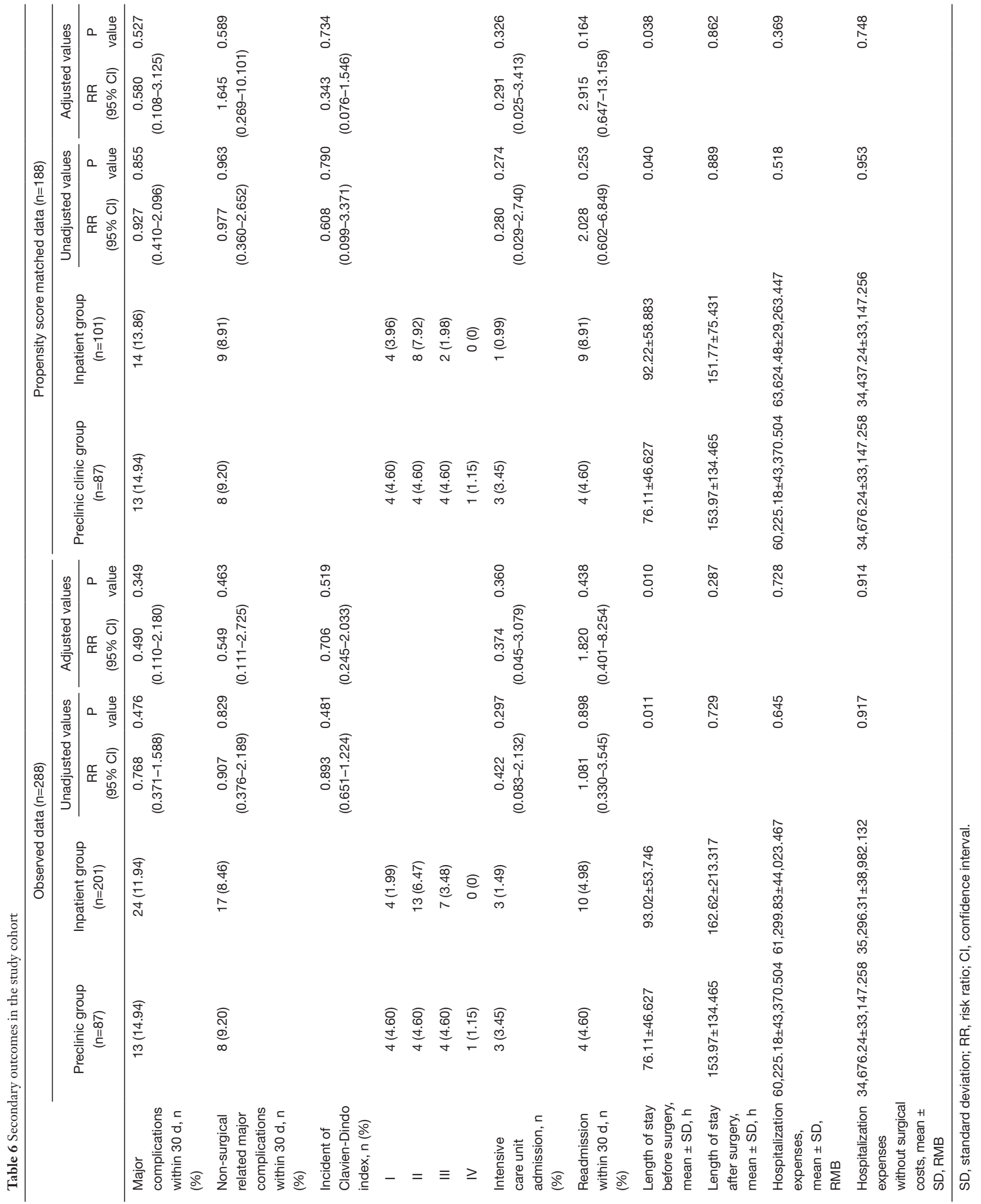


7).

\section{Discussion}

This is the first study on PACs in a tertiary teaching hospital in China. In this prospective observational study, we found that a visit to a PAC significantly reduced operation room cancellations of selective surgeries and decreased length of stays before surgery in patients with comorbidties. Meanwhile, the prognosis of those who underwent surgeries was similar in both groups, which indicates identical effectiveness of the PAC and an anesthesia consultation on patients' outcomes.

Under the condition of ambulatory and same-day surgery, PACs showed benefits in terms of reducing surgical cancellations, improving patient prognosis, saving hospital resources, reducing costs, and improving patient satisfaction $(8,16)$. The physical status of these patients could be optimized through preoperative management including comprehensive preoperative examination, medication adjustment and functional training to decrease postoperative complications (17). Preoperative assessment clinics were therefore set up to meet these functions as well as reduce cancellations and improve prognosis (18).

A prospective multicenter study showed a higher case cancellation rate in university hospitals, which might be due to the complexity of patients' medical conditions, with cancellations being costly and resulting in lost revenue as well as disrupting the throughput of cases in the operating room suit (14). Considering the above, our study was set up to focus on patients with multiple comorbidities, who were not receiving proper treatment, where the majority of cancellations and postoperative complications occurred, and who might benefit more from visits to PACs in a tertiary teaching hospital setting in China.

Most previous studies compared patients who visited PACs with those who neither visited the clinics nor received in-hospital consultations from anesthesiologists $(3,8,10)$. Our study focused on the timing of consultations. Unlike in western countries, traditionally in China surgical patients with multiple comorbidities who are not receiving proper treatment receive an anesthesia consultation after admission. With the opening of the PAC, the timing of consultations is earlier. In our study, the earlier timing of consultations as a result of the PACs visits led to a significant decrease in surgical cancellations. The cancellation rate after consultation in the inpatient group was $7.8 \%$, while all the patients admitted after visiting the PAC completed their selective surgeries. Although the previous reported incidence of cancellations varies from $2 \%$ to $27 \%$ with studies suggesting that a $<5 \%$ cancellation rate is achievable at the best-performing centers, the cancellations in our study only indicated the cancelled cases in patients with multiple comorbidities who were not receiving proper treatment $(19,20)$. Furthermore, PACs visits resulted in a shorter length of stay before surgery in our study. This may be due to the focused and detailed examination in the clinic, such that patients admitted for surgeries received full examinations (21).

In our study, unnecessary costs for admission were significantly reduced in the preclinic condition, which is consistent with previous studies (22). The cancelled cases in the preclinic group could select alternative treatments, thus reducing unnecessary costs for admissions to the surgery ward (23). Although a retrospective study on preoperative clinic visits showed reduced operating room cancellations and delays especially in older patients and patients with more medical comorbidities, it did not show reduced medical expenses (24). In this study, the average cost of any canceled case in the inpatient group was 13,057.74 RMB during hospitalization, which is about one third of per capita disposable income (32,189 RMB) in China in 2020 (15).

Previous studies showed a visit to a PAC reduced postoperative complications $(25,26)$. In our study, the similar prognosis of patients in both groups who completed the surgeries might indicate comparable effects of both PACs and in-hospital consultations from anesthesiologists on medical outcomes. At the same time, the medical status of the cancelled patients in the inpatient group was comparable to that of those who did not go through the PACs. This indicates that the same criteria were used in the PACs and in-hospital consultations.

This study showed advantages of preoperative assessment clinics for patients with multiple comorbidities as reducing operation room cancellations, length of stay before surgery as well as unnecessary costs. The anesthesiologistled PAC still leaves much to be improved (27). Firstly, multidisciplinary cooperation with other relevant medical teams should be invited since most patients in the PAC are with multidisciplinary problems. Secondary, anesthesiologist should participate more in the medical activities after operation. Patients should be recommended to visit PAC after hospital discharge for the purposes of further medical activities and follow-up.

This study has several limitations. First, the sample size was limited, because the PAC had only just been started in our center. Second, bias may exist since a visit or not visit 
Table 7 Follow-up data of laboratory examination in the study cohort

\begin{tabular}{|c|c|c|c|c|c|c|}
\hline & \multicolumn{3}{|c|}{ Observed data $(\mathrm{n}=288)$} & \multicolumn{3}{|c|}{ Propensity score matched data $(n=188)$} \\
\hline \multicolumn{7}{|l|}{$\mathrm{Hb}$, mean $\pm \mathrm{SD}, \mathrm{g} / \mathrm{L}$} \\
\hline Preoperative & $120.885 \pm 24.4870$ & $122.144 \pm 22.4438$ & 0.671 & $120.885 \pm 24.4870$ & $118.933 \pm 24.4454$ & 0.494 \\
\hline Postoperative day 1 & $111.828 \pm 19.7208$ & $113.401 \pm 20.6150$ & 0.547 & $111.828 \pm 19.7208$ & $110.792 \pm 22.2326$ & 0.738 \\
\hline Postoperative day 28 & $116.064 \pm 19.7312$ & $115.923 \pm 19.4773$ & 0.967 & $116.064 \pm 19.7312$ & $116.513 \pm 19.0023$ & 0.899 \\
\hline \multicolumn{7}{|l|}{$\mathrm{ALT}$, mean $\pm \mathrm{SD}, \mathrm{U} / \mathrm{L}$} \\
\hline Preoperative & $17.996 \pm 11.4987$ & $17.577 \pm 10.2120$ & 0.776 & $17.996 \pm 11.4987$ & $17.827 \pm 9.1677$ & 0.996 \\
\hline Postoperative day 1 & $21.839 \pm 12.3692$ & $23.277 \pm 19.9657$ & 0.534 & $21.839 \pm 12.3692$ & $22.188 \pm 18.1812$ & 0.880 \\
\hline Postoperative day 28 & $30.574 \pm 23.7318$ & $24.026 \pm 16.0996$ & 0.162 & $30.574 \pm 23.7318$ & $23.863 \pm 13.6203$ & 0.125 \\
\hline \multicolumn{7}{|l|}{$\mathrm{AST}$, mean $\pm \mathrm{SD}, \mathrm{U} / \mathrm{L}$} \\
\hline Preoperative & $20.310 \pm 7.0699$ & $20.284 \pm 8.0302$ & 0.979 & $20.310 \pm 7.0699$ & $20.702 \pm 7.8492$ & 0.616 \\
\hline Postoperative day 1 & $21.138 \pm 7.4399$ & $25.351 \pm 31.3240$ & 0.217 & $21.138 \pm 7.4399$ & $22.901 \pm 26.4059$ & 0.548 \\
\hline Postoperative day 3 & $29.562 \pm 36.1210$ & $24.304 \pm 22.0538$ & 0.524 & $29.562 \pm 36.1210$ & $21.126 \pm 18.0709$ & 0.447 \\
\hline Postoperative day 14 & $37.973 \pm 23.8339$ & $24.727 \pm 22.4143$ & 0.250 & $37.973 \pm 23.8339$ & $22.011 \pm 10.0327$ & 0.230 \\
\hline Postoperative day 28 & $28.957 \pm 23.8828$ & $27.547 \pm 15.1131$ & 0.651 & $28.957 \pm 23.8828$ & $27.750 \pm 13.5745$ & 0.717 \\
\hline \multicolumn{7}{|l|}{ TBil, mean $\pm \mathrm{SD}, \mu \mathrm{mol} / \mathrm{mL}$} \\
\hline \multicolumn{7}{|l|}{$A L B$, mean $\pm S D, g / L$} \\
\hline Preoperative & $42.517 \pm 5.6480$ & $40.995 \pm 5.1396$ & 0.026 & $42.517 \pm 5.6480$ & $40.981 \pm 6.2566$ & 0.099 \\
\hline Postoperative day 1 & $36.287 \pm 5.0392$ & $36.025 \pm 5.0534$ & 0.685 & $36.287 \pm 5.0392$ & $35.634 \pm 5.2014$ & 0.385 \\
\hline Postoperative day 3 & $37.731 \pm 3.8193$ & $37.680 \pm 5.5200$ & 0.955 & $37.731 \pm 3.8193$ & $37.726 \pm 4.4660$ & 0.983 \\
\hline Postoperative day 14 & $41.953 \pm 6.6199$ & $42.053 \pm 5.3140$ & 0.907 & $41.953 \pm 6.6199$ & $42.705 \pm 4.7613$ & 0.417 \\
\hline Postoperative day 28 & $44.340 \pm 6.8850$ & $43.368 \pm 5.9199$ & 0.366 & $44.340 \pm 6.8850$ & $44.200 \pm 6.4029$ & 0.908 \\
\hline \multicolumn{7}{|l|}{$\mathrm{Cr}$, mean $\pm \mathrm{SD}, \mu \mathrm{mol} / \mathrm{mL}$} \\
\hline Preoperative & $89.908 \pm 64.8463$ & $102.378 \pm 99.3884$ & 0.284 & $89.908 \pm 64.8463$ & $116.029 \pm 142.0791$ & 0.103 \\
\hline Postoperative day 1 & $89.149 \pm 82.7828$ & $100.851 \pm 106.6365$ & 0.363 & $89.149 \pm 82.7828$ & $105.653 \pm 118.0925$ & 0.276 \\
\hline Postoperative day 3 & $89.025 \pm 86.5813$ & $96.923 \pm 90.4982$ & 0.511 & $89.025 \pm 86.5813$ & $103.084 \pm 110.2644$ & 0.356 \\
\hline Postoperative day 14 & $89.391 \pm 79.0494$ & $98.007 \pm 74.1941$ & 0.447 & $89.391 \pm 79.0494$ & $99.727 \pm 73.9850$ & 0.410 \\
\hline Postoperative day 28 & $78.745 \pm 27.1473$ & $84.198 \pm 36.8735$ & 0.360 & $78.745 \pm 27.1473$ & $86.225 \pm 41.8690$ & 0.275 \\
\hline
\end{tabular}

$\mathrm{SD}$, standard deviation; Hb, hemoglobin; ALT, aminoleucine transferase; AST, aspartate aminotransferase; Tbil, total bilirubin; ALB, albumin; Cr, creatinine. 


\section{Page 10 of 11}

to the PAC was recommended by surgeons who did not fully recognize the function of a PAC. Finally, the detailed reasons for cancellation for each cancelled case were not documented.

For patients with multiple comorbidities, a visit to a PAC compared with an anesthesia consultation after admission could reduce operating room cancellations as well as unnecessary admissions and additional medical expenses. This means that PACs are more benefit for patients with multiple comorbidities. These findings may support the development of PACs in China and lead to further advances in the perioperative setting.

\section{Acknowledgments}

We are grateful to Fei Liang and Yihan Lu for guidance on statistical analyses. We are grateful to the surgeons, who participate in this research.

Funding: This study is supported by the Shanghai Municipal Key Clinical Specialty (No.: shslczdzk03603).

\section{Footnote}

Reporting Checklist: The authors have completed the STROBE reporting checklist. Available at https://dx.doi. org/10.21037/atm-21-4665

Data Sharing Statement: Available at https://dx.doi. org/10.21037/atm-21-4665

Conflicts of Interest: All authors have completed the ICMJE uniform disclosure form (available at https://dx.doi. org/10.21037/atm-21-4665). The authors have no conflicts of interest to declare.

Ethical Statement: The authors are accountable for all aspects of the work in ensuring that questions related to the accuracy or integrity of any part of the work are appropriately investigated and resolved. All procedures performed in this study involving human participants were in accordance with the Declaration of Helsinki (as revised in 2013). The study was approved by ethics board of clinical trial (No.: NCT03665987) and informed consent was taken from all the patients.

Open Access Statement: This is an Open Access article distributed in accordance with the Creative Commons Attribution-NonCommercial-NoDerivs 4.0 International

\section{Liu et al. Preoperative assessment clinics and case cancellations}

License (CC BY-NC-ND 4.0), which permits the noncommercial replication and distribution of the article with the strict proviso that no changes or edits are made and the original work is properly cited (including links to both the formal publication through the relevant DOI and the license). See: https://creativecommons.org/licenses/by-nc-nd/4.0/.

\section{References}

1. Hepner DL, Bader AM, Hurwitz S, et al. Patient satisfaction with preoperative assessment in a preoperative assessment testing clinic. Anesth Analg 2004;98:1099-105.

2. Parker BM, Tetzlaff JE, Litaker DL, et al. Redefining the preoperative evaluation process and the role of the anesthesiologist. J Clin Anesth 2000;12:350-6.

3. van Klei WA, Moons KG, Rutten CL, et al. The effect of outpatient preoperative evaluation of hospital inpatients on cancellation of surgery and length of hospital stay. Anesth Analg 2002;94:644-9.

4. Miller-Hoehl DA. Patient satisfaction and quality care. Caring 1992;11:34-7.

5. Tait AR, Voepel-Lewis T, Munro HM, et al. Cancellation of pediatric outpatient surgery: economic and emotional implications for patients and their families. J Clin Anesth 1997;9:213-9.

6. Ljungqvist $\mathrm{O}$, Søreide E. Preoperative fasting. Br J Surg 2003;90:400-6.

7. Available online: http://www.nhc.gov.cn/yzygj/s3593/2017 12/251fb61008bc487797ed18a3a15c1337.shtml

8. Knox M, Myers E, Hurley M. The impact of pre-operative assessment clinics on elective surgical case cancellations. Surgeon 2009;7:76-8.

9. Kopp VJ. Preoperative preparation. Value, perspective, and practice in patient care. Anesthesiol Clin North Am 2000;18:551-74.

10. Ferschl MB, Tung A, Sweitzer B, et al. Preoperative clinic visits reduce operating room cancellations and delays. Anesthesiology 2005;103:855-9.

11. Correll DJ, Bader AM, Hull MW, et al. Value of preoperative clinic visits in identifying issues with potential impact on operating room efficiency. Anesthesiology 2006;105:1254-9; discussion 6A.

12. Harnett MJ, Correll DJ, Hurwitz S, et al. Improving efficiency and patient satisfaction in a tertiary teaching hospital preoperative clinic. Anesthesiology 2010;112:66-72.

13. Halaszynski TM, Juda R, Silverman DG. Optimizing postoperative outcomes with efficient preoperative assessment and management. Crit Care Med 
2004;32:S76-86.

14. Schuster M, Neumann C, Neumann K, et al. The effect of hospital size and surgical service on case cancellation in elective surgery: results from a prospective multicenter study. Anesth Analg 2011;113:578-85.

15. Available online: http://www.stats.gov.cn/ztjc/zthd/ lhfw/2021/lh_hgjj/202103/t20210301_1814216.html

16. Yen C, Tsai M, Macario A. Preoperative evaluation clinics. Curr Opin Anaesthesiol 2010;23:167-72.

17. Sweitzer BJ. Preoperative screening, evaluation, and optimization of the patient's medical status before outpatient surgery. Curr Opin Anaesthesiol 2008;21:711-8.

18. Koris J, Hopkins C. Improving the quality of the surgical preoperative assessment in a district general hospital. BMJ Qual Improv Rep 2015;4:u205381.w3406.

19. Morris AJ, McAvoy J, Dweik D, et al. Cancellation of Elective Cases in a Recently Opened, Tertiary/ Quaternary-Level Hospital in the Middle East. Anesth Analg 2017;125:268-71.

20. Macario A. Are your hospital operating rooms "efficient"? A scoring system with eight performance indicators. Anesthesiology 2006;105:237-40.

21. Kluger MT, Tham EJ, Coleman NA, et al. Inadequate pre-operative evaluation and preparation: a review of 197

Cite this article as: Liu S, Lu X, Jiang M, Li W, Li A, Fang F, Cang J. Preoperative assessment clinics and case cancellations: a prospective study from a large medical center in China. Ann Transl Med 2021;9(19):1501. doi: 10.21037/atm-21-4665 reports from the Australian incident monitoring study. Anaesthesia 2000;55:1173-8.

22. Pinzur MS, Gurza E, Kristopaitis T, et al. Hospitalistorthopedic co-management of high-risk patients undergoing lower extremity reconstruction surgery. Orthopedics 2009;32:495.

23. Edwards AF, Slawski B. Preoperative Clinics. Anesthesiol Clin 2016;34:1-15.

24. Vazirani S, Lankarani-Fard A, Liang LJ, et al. Perioperative processes and outcomes after implementation of a hospitalist-run preoperative clinic. J Hosp Med 2012;7:697-701.

25. Wijeysundera DN. Preoperative consultations by anesthesiologists. Curr Opin Anaesthesiol 2011;24:326-30.

26. Blitz JD, Kendale SM, Jain SK, et al. Preoperative Evaluation Clinic Visit Is Associated with Decreased Risk of In-hospital Postoperative Mortality. Anesthesiology 2016;125:280-94.

27. Tariq H, Ahmed R, Kulkarni S, et al. Development, Functioning, and Effectiveness of a Preoperative Risk Assessment Clinic. Health Serv Insights 2016;9:1-7.

(English Language Editor: B. Meiser) 